\title{
Preparo de rufiões ovinos por fixação da curvatura caudal da flexura sigmóide do pênis
}

\section{Ovine teaser preparation by caudal curvature fixation of the penis sigmoid flexure}

\author{
Duvaldo Eurides,' Alexandre Mazzanti," Luiz Antônio Franco da Silva,," \\ Maria Clorinda Soares Fioravanti, "**" Nilo Sérgio Troncoso Neto ${ }^{* \ldots * *}$
}

\begin{abstract}
Resumo
Utilizou-se 10 ovinos, machos, sem raça definida, com idades de 8 a 14 meses para preparo de rufiões. A túnica albugínea da face lateral da curvatura caudal da flexura sigmóide do pênis e um segmento do corpo do pênis proximal à raiz foram escarificados e aproximadas com três pontos simples separados com fio de náilon. Decorridos 25 dias da intervenção cirúrgica, os rufiões foram observados em presença de fêmeas em cio, apresentando boa libido e total incapacidade de exposição do pênis. O método descrito foi de fácil execução, podendo ser utilizado com eficiência na prática de preparo de rufiões ovinos.
\end{abstract}

Palavras-chave: ovino; rufião; pênis; cirurgia.

\section{Introdução}

A inseminação artificial é um fator importante para obtenção de índices que resultem num melhoramento genético e zootécnico nos animais domésticos. Entretanto, falhas na identificação e controle de cio têm impedido o sucesso de programas de inseminação artificial e monta controlada, ocasionando atraso na parição e início da lactação, refletindo em perdas econômicas para o produtor (Arbeiter et al., 1965 ; Eurides et al., 1992). Em rebanho bovino preparado para inseminação artificial, a presença do rufião tem por objetivo detectar o estro e estimular a ovulação (Arbeiter et al., 1965 ; Grommers e Elving, 1978). Shelton (1960) observou, em rebanho caprino, que a presença de rufiões pode estimular o aparecimento de cio.

Vários são os métodos empregados para o preparo de rufiões bovinos, como interrupção do ejaculado através da secção e ligadura do epidídimo (Tharp, 1955 ; Smith, 1967 ; Blockey, 1968), aderência da túnica albugínea do pênis à parede abdominal ventral (Belling, 1961; Forgason, 1963 ; Castro et al., 1994), desvio ventral do prepúcio (Grabowski e Rutkowiak, 1969), novo óstio prepucial no terço médio lateral do prepúcio (Carneiro, 1975), aderência da curvatura caudal da flexura sigmóide do pênis
(Eurides e Pippi, 1983), desvio lateral de pênis (Arbeiter et al., 1965 ; Jochle et al., 1973 ; Merkt e Sampaio, 1973 ; Royes e Bivin, 1973 ; Ostrowski e Rutter, 1974) e novo óstio prepucial na linha mediana ventral do prepúcio (Smith, 1963).

No preparo de rufiões ovinos, Dum (1963) e Sbernardori (1974a) utilizaram a técnica de epididimectomia e observaram em alguns casos difusão de doenças venéreas, epididimite e possibilidade de recanalinazação do epidídimo. No método de encurtamento dos músculos retratores do pênis, Sbernardori (1974b) verificou a possibilidade de recuperação destes músculos com exposição do pênis e realização de cópulas. Castro (1983) e Scull et al. (1990) propuseram a técnica de fixação da túnica albugínea do pênis na linha mediana ventral da parede abdominal e relataram que o método impediu a transmissão de doenças venéreas. Na técnica de desvio lateral do pênis, formando um ângulo de 45 graus com a linha mediana ventral, Jochle et al. (1973) e Ball et al. (1978) verificaram, em alguns casos, formação de edema na região ventral da bolsa escrotal e retenção de urina na lã próximo à região operada. Em carneiro, a transposição do óstio prepucial para a bolsa escrotal não alterou a libido dos rufiões (Eurides et al., 1983).

\footnotetext{
'Médico Veterinário, Professor Titular, Doutor. Departamento de Medicina Animal. Curso de Medicina Veterinária. Universidade Federal de Uberlândia/UFU.

“ Médico Veterinário Residente. Hospital Veterinário. Curso de Medicina Veterinária/UFU.

... Médico Veterinário, Professor Adjunto, Doutor. Departamento de Clínica. Escola de Veterinária/EV. Universidade Federal de Goiás/UFG.

.... Médica Veterinária, Professora Assistente. Mestre. EV/UFG.

..... Médico Veterinário, Professor Titular, Doutor. EV/UFG.
} 
Este experimento teve por objetivo verificar o comportamento e a viabilidade da técnica de preparo de rufiões ovinos, utilizando o método de fixação da curvatura caudal da flexura sigmóide a um segmento do corpo do pênis proximal à sua raiz, conforme descrito por Eurides e Pippi (1983) em bovinos. O método foi avaliado através do comportamento sexual, incapacidade de exposição peniana e realização de cópula.

\section{Material e métodos}

Foram utilizados 10 ovinos machos, sem raça definida, com idade de 8 a 14 meses e peso variando de 30 a $40 \mathrm{~kg}$. Os animais foram previamente observados em monta natural para avaliação da libido sexual e possíveis alterações clínico-patológicas dos órgãos genitais externos. Após jejum completo de 12 horas, cada animal recebeu como medicação pré-anestésica cloridrato de xilazina $^{1}$ a $2 \%(0,3 \mathrm{mg} / \mathrm{kg}$ de peso corporal), via intramuscular (IM). Foram contidos em decúbito lateral, com os membros pélvicos e torácicos atados juntos e a região perineal foi submetida a tricotomia e antisepsia com álcool iodado a $2 \%$. Foi administrado cloridrato de lidocaina ${ }^{2}$ a $2 \%$, sem vasoconstrictor, como anestésico local através do método de infiltração subcutânea e profunda na linha de incisão. Com bisturi foi feita uma incisão de pele na linha mediana perineal de aproximadamente $6,0 \mathrm{~cm}$ de comprimento, iniciada cerca de $4,0 \mathrm{~cm}$ dorsal à base do escroto (Figura 1). A união dos músculos semimembranáceos foi seccionada com tesoura para localização dos músculos retratores do pênis que foram mantidos tracionados. A curvatura caudal da flexura

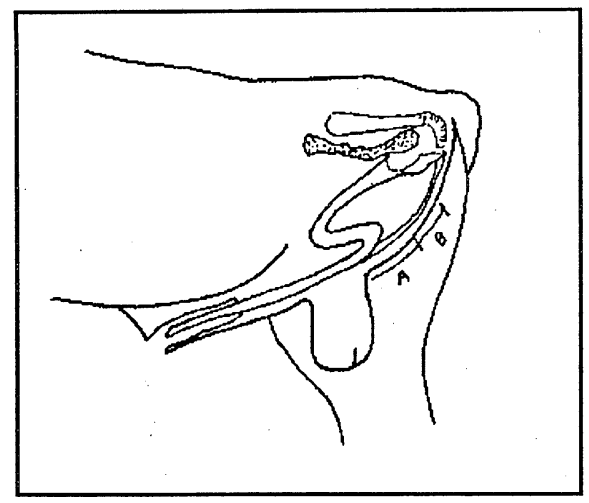

Figura 1: Esquema representando o local de incisão de pele na região mediana perineal $(B)$ e distância da bolsa testicular para início de incisão de pele (A) para preparação de rufiões ovinos. sigmóide do pênis foi exposta por divulsão digital dos tecidos adjacentes. Com uma pinça hemostática curva de Kelly, foi exposto um segmento do corpo do pênis proximal à raiz.

A túnica albugínea da face lateral da curvatura caudal da flexura sigmóide e do segmento do corpo do pênis proximal à sua raiz foram escarificadas com bisturi. Foram aplicados três pontos simples separados de fio de náilon ${ }^{3} 0$ passando ao corpo cavernoso do pênis aproximando as porções escarificadas (Figura 2). Após reintrodução da flexura sigmóide do pênis ao seu local de origem, os músculos semimembranáceos e o tecido subcutâneo foram aproximados com ponto simples separados de fio categute $1 \mathrm{e}$ a pele com pontos Wolff de fio de algodão 0 .

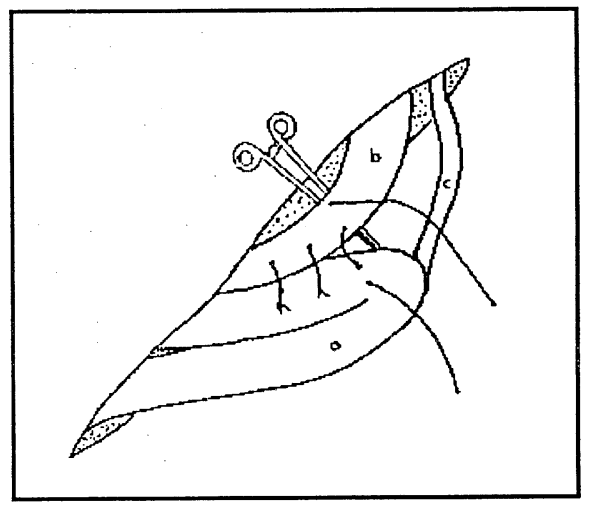

Figura 2: Esquema representativo das faces laterais da túnica albugínea da curvatura caudal da flexura sigmóide (a) e de um segmento do corpo do pênis (b) proximal à sua raiz aproximadas com pontos simples separados e do músculo retrator do pênis (c) em ovino.

No pós-operatório, foi administrado a cada animal cloridrato de oxitetraciclina ${ }^{6}(22 \mathrm{mg} / \mathrm{kg}$ de peso corporal), $\mathrm{IM}$, dose única e aplicação diária na ferida de pele de permanganato de potássio na diluição 1:3000 e polivinilpirrolidona ${ }^{7}$ durante dez dias. Os pontos de pele foram removidos aos 12 dias de pós-operatório, sendo os animais isolados das fêmeas por um período de25 dias. Passado este período, foram avaliados como rufiões em um rebanho de matrizes durante dez meses.

\section{Resultados}

A administração do cloridrato de xilazina, por via intramuscular, permitiu a contenção dos animais com os membros pélvicos tracionados cranialmente, o que facilitou a aplicação da anestesia local e realização da técnica operatória, independentemente de estarem em decúbito lateral direito ou esquerdo.

\footnotetext{
${ }^{1}$ Rompum. Bayer do Brasil. São Paulo, SP.

${ }^{2}$ Xylocaina. Astra Química do Brasil, São Paulo, SP.

${ }^{3}$ Ethicon. Johnson \& Johnson, São José do Rio Preto, SP.

${ }^{4}$ Categute. Bruneau, São Bernardo do Campo, SP.
}

${ }^{5}$ Fio de Algodão. Linhas Corrente, São Paulo, SP.
${ }^{6}$ Terramicina LA. Pfizer, Guarulhos, SP.
${ }^{7}$ Riodeine. Rioquímica, São José do Rio Preto, SP. 
A localização, extensão da incisão de pele na linha mediana perineal e da união dos músculos semimem-branáceos permitiram a identificação dos músculos retratores do pênis e a divulsão digital dos tecidos adjacentes facilitou a exposição da flexura sigmóide, sem que se notasse áreas extensas de hemorragia e formação aparente de edema no pós-operatório.

A aproximação da face lateral da curvatura caudal da flexura sigmóide com a do segmento do corpo do pênis, proximal a sua raiz, com pontos simples separado de náilon permitir aderências das túnicas albgíneas.

Durante o período de observação de dez meses num rebanho de matrizes, os rufiões apresentaram bom comportamento sexual com total incapacidade de exposição de pênis e realização de cópula. A glande do pênis dos rufiões permaneceu afastada caudalmente do óstio prepucial, mantendo-se próximo da bolsa testicular.

\section{Discussão}

O uso isolado de tranqüilizante empregado por Carneiro (1975), como medicação pré-anestésica para a intervenção cirúrgica de preparo de rufiões bovinos, não deve ser suficiente para impedir manifestações dolorosas. Nesta pesquisa, no entanto, utilizou-se como medicação pré-anestésica o cloridrato de xilazina ${ }^{1}$ a $2 \%$ associado à anestesia local por infiltração na linha mediana perineal, o que permitiu a realização da operação sem manifestações de sensibilidades dolorosas, coincidindo com as observações de Pompermayer et al. (1993), na técnica de desvio do óstio prepucial para a região ventro-lateral do abdômen no preparo de rufiões caprinos.

$\mathrm{Na}$ técnica cirúrgica utilizada, não foram observados hemorragia ou formação de edema pós-operatório. No entanto, métodos de desvio lateral de pênis de bovinos descrito por Arbeiter et al. (1965), Jochle et al. (1973), Merkt e Sampaio (1973) e Royes e Bivin (1973), podem ocasionar hemorragias acentuadas e edema da região permitindo complicações locais de pós-operatório, como relatado por Ostrowsky e Rutter (1974). O preparo de rufiões através da fixação do pênis à parede abdominal (Belling, 1961; Forgasson, 1963; Castro et al., 1994) pode também apresentar formação de edema por ser realizada na superfície ventral do abdômen.

Foi referido por Shipilov (1964), Grabowsky e Rutkowiak (1969), Jochle et al. (1973), Merkt e Sampaio (1973), Ball et al. (1978) e Pompermayer et al. (1993) que os métodos de desvio lateral do pênis podem ocasionar retenção de urina. Nos animais deste experimento, apesar da sutura de aproximação da face lateral da curvatura caudal com a de um segmento do corpo do pênis proximal à raiz ter sido realizada próxima à uretra, não foi verificado traumatismo e nem retenção de urina durante o período de dez meses de observação.
Neste experimento, a utilização do fio de náilon 0 na aproximação da face lateral das túnicas albugíneas permitiu boa fixação das estruturas envolvidas durante o período de observação, sem complicações locais de pós-operatório. A eficiência da fixação com fio de náilon coincide com os resultados obtidos na técnica utilizada por Castro (1983), com fio de algodão fixando a túnica albugínea do pênis à parede abdominal ventral em ovinos e de Eurides e Pippi (1983), que fixaram a curvatura caudal da flexura sigmóide de pênis de bovinos, verificando que o fio de algodão foi seguro e não provocou alterações macroscópicas indesejáveis.

No preparo de rufiões ovinos, Dum (1963) e Sbernardori (1974a) afirmaram que a técnica de epididimectomia permitiu a exposição do pênis e realização de cópula. Já o método empregado neste experimento manteve a glande do pênis afastada do óstio prepucial, permanecendo próximo da bolsa testicular, não sendo necessário, portanto, associar à técnica de vasectomia ou epididimectomia como recomendado por Aanes e Rupp (1984).

Em bovinos, a técnica de formação de novo orifício prepucial, na linha mediana ventral, caudalmente ao óstio prepucial, foi utilizada por Smith (1963) que recomenda que os animais sejam submetidos à vasectomia, devido à possibilidade de realização de cópula. Shires (1977) afirma que, além da fertilização, existe a possibilidade da transmissão de doenças venéreas através do coito, demonstrando outra vantagem do método de fixação do pênis.

Neste experimento, quando observados em rebanho de matrizes em cio por um período de dez meses, os animais apresentaram bom comportamento sexual, coincidindo com as observações feitas por Royes e Bivin (1973) no preparo de rufiões bovinos. Os métodos de preparo de rufiões que impedem a realização de cópula podem ocasionar diminuição da libido com o passar do tempo (Jochle et al., 1973; Merkt e Sampaio, 1973), o que pode ser evitado, segundo Carneiro (1975), fazendo os animais ejacularem uma a duas vezes por mês, com objetivo de estimular as funções sexuais. A substituição de cópulas por ejaculados programados provavelmente não será suficientemente capaz de estimular a libido dos rufiões. $O$ aparecimento da diminuição da libido torna inevitável a troca do rufião, de modo que o emprego do método proposto neste experimento pode ser indicado por apresentar baixo custo, eficiência e simplicidade de aplicação.

\section{Conclusões}

O acesso cirúrgico na linha mediana perineal, realizado a $6,0 \mathrm{~cm}$ da base da bolsa testicular, facilita a exposição de um segmento do corpo do pênis e da flexura sigmóide. A divulsão digital utilizada para exposição da curvatura caudal da flexura sigmóide do pênis ocasiona pouco sangramento, que é facilmente controlado. 
A fixação da curvatura caudal da flexura sigmóide do pênis com fio de náilon para aproximação das túnicas albugíneas mantém a glande do pênis afastada do óstio prepucial e impede a exposição do pênis. Os pontos de sutura aplicada com fio náilon para aproximação das túnicas albugíneas da flexura sigmóide e de um segmento do corpo do pênis são eficazes por impedir a exposição de pênis por um período de 10 meses.

Os ovinos operados mantiveram a libido durante o período experimental de observação, com total incapacidade de exposição de pênis.

\section{Abstract}

Ten adult male, with no breed ovines, eight to ten months old were used to prepare of ovine teasers. The tunica albuginea from the caudal sigmoid curvature and from a distal segment of the cranial sigmoid curvature were stitched together with four simple and separeted stitches of cotton thread. After 25 days of surgery, the teaser were tested with females in estrus period. The teaser proved to have good libido and incapacity to exteriorize the penis. The method was easy to perform and can be used to prepare ovine teasers.

Keywords: ovine; teaser; penis; surgery.

\section{Referências bibliográficas}

ARBEITTER, K., GLAWISCHNIG, E.,ZINNBAUER, H. Surgical displacement of the bull's penis. Sterile copulation for the stimulation of oestrus and ovulation in cow. Wien. Tierarztl. Mschr., v. 52, no. 13, p. 765-773, 1965.

AANES, W.A, RUPP, G. latrogenic preputial stenosis for preparation of the teaser bulls. J. Am. Vet. Med. Assoc., v. 184, no. 12, p. 1474-1476, 1984.

BALL, P.J., WILSON, T.F., FOOTE, R.H. Detection of oestrus na quality of semen produced bay rams with deviated penis. Theriogenology, v. 9, no. 5, p. 457-462, 1978.

BELLING, T.H. Preparation of the teaser bull for use in beef catlle artificial insemination program. J. Am. Vet. Med. Assoc., v. 138, no. 12, p. 670-672, 1961.

BLOCKEY, M.A.B. Sterilization of bulls for use as teaser. N. $Z$. Vet J., v. 17, no. 70, 1968.

CARNEIRO, M.I. Preparação de rufiões bovinos. Técnicas cirúrgicas para formação de novo óstio prepucial. Col. bras. Rep. Anim., v. 1, p. 2-24, 1975.

CASTRO, M. J. Preparo de rufiões ovinos por fixação da túnica albugínea do pênis na parede ventro-abdominal. 1983. 24 f. Dissertação (Mestrado em Cirurgia) - Universidade Federal de Santa Maria, 1983.

CASTRO, M.A.S., MARÇAL, A.V., MIDON FILHO, I. Preparo de rufiões bovinos pela fixação do corpo do pênis na parede ventro-medial do abdomen. R. Fac. Zoot. Vet. Agron., v.1, n.1, p. 43-48, 1994.

DUM, R.E. Sterilization of rams lambs. Aust. Vet. J., v. 39, no.1, p. 38, 1963.

EURIDES, D., CONTESINI, E.E., VIANA, S.M. Preparação de rufiões bovinos por remoção do ligamento apical do pênis. $R$. Cent. Ci. Rur., v. 22, n. 2, p. 185-189, 1992.

EURIDES, D., PIPPI, N.L. Preparação de rufiões bovinos por fixação da curvatura caudal da flexura sigmóide do pênis. $R$. Cent. Ci. Rur., v. 13, n. 1, p. 83-93, 1983.

EURIDES, D. et al. Transposição do óstio prepucial para bolsa escrotal em carneiros. Veritas, v. 28, n. 112, p. 475-481, 1983.

FORGASON, J.L. Winrock farm beef catlle improvement program. Vet. Med., v. 53, no. 3, p. 211-216, 1963.

GRABOWSKY, K., RUTKOWIAK, B. The preparation of bulls as test animals according to the own method of teaser bulls by chirurgical plastic of prepuce. Med. Vet., v. 25, no. 9, p. 551-553, 1969.
GROMMERS, F.J., ELVING, L. Evaluation of surgical lateral desviation of the penis in teaser bulls. Tijdschr. Diergeneesr., v. 103 , no. 3 , p. 187-190, 1978.

JOCHLE, W. et al. Preparation of teaser bulls rams and boars by penis and prepuce desviation. Vet. Med. Small Anim. Clin., v. 68, no. 4, p. 395-400, 1973.

MERKT, J.G., SAMPAIO, F.A .Suchbullen durch penisablenkung nach operativer verlagerung des praeputiums. Dtsch. Tierarztl. Wschr., v. 80, no. 22, p. 515-519, 1973.

OSTROWSKY, J.E.B., RUTTER, B. Surgical lateral displacement of the penis of bulls to be used as teaser. Gaceta Vet., v. 36, no. 293, p. 652-659, 1974.

POMPERMAYER, L.G., ESPESCHIT, C.J.B, BORGES, A.P.B. Preparo de rufiões caprinos pela técnica do transplante do óstio prepucial para a prega inguinal. Arq. bras. Med. Vet. Zoot., v. 43 , n. 3, p. 305-313, 1993.

ROYES, B.A P., BIVIN, W.S. Surgical displacement of the penis in the bull. J. Am. Vet. Med. Assoc., v. 16, no. 1, p. 56-57, 1973.

SBERNARDORI, U. Caudal epididymotomy and epidimectomy in the rams. Clinica Vet., v. 97, no. 10, p. 333-336, 1974a.

Surgical shortening of the retractor penis muscles to prepare rams for use a teaser. Clinica Vet., v. 97, no. 10 , p. 329-332, 1974b.

SCULL, J., VILLALOBOS, R., BENITEZ, R. Descripción de una técnica operatoria para la retración y fijación del pene en los machos ovinos y su posterior utilización como receladores. Rev. Cub. Reprod. Anim., v.16, n. 1, p. 9-14, 1990.

SHELTON, M. Influence of the presence of a male goat on the initiation of estrous cycling and ovulation of Angora does. J. Anim. Sci., v. 19, no. 2, p. 368-375, 1960.

SHIPILOV, V.C. Surgical method for the permanent lateral fixation of the bulls prepuce and penis. Veterinaria Moscou, v. 41, no. 8, p. 60-64, 1964 .

SHIRES, G.M.H. Another surgical method of preparing heatdetector bulls. lowa State University Veterinarin, v. 39, no. 2 , p. 50, 1977.

SMITH, A.P. Epididymal transection for sterilizing bulls. J. Am. Vet. Med. Assoc., v. 150, no. 6, p. 633, 1967.

SMITH, L.C. Surgical prodecures to make a bull a heat detector. A. I. Digest., v. 9, no. 1, p. 1, 1963.

THARP, V.L. Vasectomy in the bull. J. Am. Vet. Med. Assoc., v. 126, no. 935, p. 96-99, 1955. 